\title{
Trends, inequalities and determinants of low birth weight in Sri Lanka
}

\author{
C Anuranga 1 , R Wickramasinghe ${ }^{1}$, R P Rannan-Eliya ${ }^{1}$, S M M Hossain ${ }^{2}$, A T P L Abeykoon ${ }^{1}$ \\ (Index words: low birth weight, nutrition, inequality)
}

\begin{abstract}
Introduction This study analyses the DHS 1993, 2000 and 2006-07 and NFSS 2009 survey data to investigate trends, inequalities and determinants of low birth weight (LBW) in Sri Lanka.

Methods We re-evaluated recent trends in LBW incidence, adjusting for changes in the coverage of DHS surveys to ensure comparability, and used multivariate logistic regression to investigate determinants. We quantified the degree of economic inequality using wealth and concentration indices, and assessed the contribution of determinants to inequality by decomposition.
\end{abstract}

Results There was a continuing, but slowing decline in LBW incidence, reaching 17\% during 2001/02-2006/07, whilst very low birth weight incidence declined from $0.9 \%$ to $0.6 \%$. Concentration indices reveal persistent, large economic inequalities in LBW incidence. Maternal body mass index (BMI), height and education, altitude and Indian Tamil ethnicity were the major determinants of LBW, with supply of 'Thriposha' having no significant impact. Accounting for maternal BMI and height largely eliminates the impact of economic status, and reduces the impact of ethnicity. Decomposition analysis reveals the major contributors to the inequalities are maternal BMI $(21 \%)$, height $(12 \%)$ and education (14\%), ethnicity $(9 \%)$ and altitude $(7 \%)$.

Conclusions The results imply that food insecurity mediates the association of LBW with poverty, and is the major amenable risk factor. The impact of maternal height and Indian Tamil ethnicity suggests that epigenetic mechanisms play a role, and that reductions in LBW incidence will take considerable time. There is a need to substantially improve the effectiveness of interventions to reduce LBW in coming generations.

Ceylon Medical Journal 2012; 57: 61-69

\section{Introduction}

Low birth weight (LBW), defined as birth weight $(\mathrm{BW})<2,500 \mathrm{~g}$, is a major risk factor for child undernutrition, with long-term sequelae, including impaired cognitive development and increased adulthood risks of noncommunicable diseases (NCD), such as diabetes and dementia [1, 2]. Preterm birth accounts for half the LBW incidence in developed countries, but in developing countries, the primary pathway is intrauterine growth retardation (IUGR) caused primarily by maternal undernutrition, and other factors [2,3] (Table 1).

LBW incidences have declined in Sri Lanka, but the reliability of trends reported by Sri Lanka's Demographic and Health Surveys (DHS) has been questioned, owing to changes in coverage. Nevertheless, the reported incidence of $17 \%$ in the most recent DHS surveys is high in comparison with countries at similar income levels, although this is true of all South Asian countries [4]. Lagging progress on child nutrition, despite investments in maternal nutrition and universal access to antenatal care, led the government in 2011 to establish a National Nutrition Council to formulate new strategies. Given the contribution of LBW to later morbidity and to social disadvantage, LBW trends and determinants must be monitored to inform policy.

\section{Methods}

We used data from the DHS surveys of the Department of Census and Statistics with BW information: 1993, 2000 and 2006-07, and the Medical Research Institute's Nutrition and Food Security Survey (NFSS) 2009 [5-8]. These sampled ever-married, 15-49 years old women and their children. The DHS surveys excluded the Eastern (EP) and Northern (NP) Provinces, except for the DHS 2006-07, which included EP. The NFSS 2009 used a two-stage, cluster sample design to survey 13 districts from all nine provinces, but its design does not support reliable national inferences. All surveys collected BW data of all living children born in the previous 5 years to sampled mothers. The source was the child health card, which was available for more than $90 \%$ of all children in each survey, except the DHS 1993, where maternal recall provided 18\% of records.

${ }^{1}$ Institute for Health Policy, Colombo, Sri Lanka, ${ }^{2}$ UNICEF, Sri Lanka

Correspondence: RPRE, e-mail: <raviofficelk@gmail.com>. Received 12 July 2011 and revised version accepted 8 February 2012. Competing interests: none declared. 
Table 1. Summary of literature on determinants of low birth weight and previous findings from Sri Lanka

\begin{tabular}{|c|c|c|c|}
\hline Determinants $^{1}$ & $\begin{array}{c}\text { Strength of } \\
\text { association }^{2}\end{array}$ & $\begin{array}{l}\text { Previously reported } \\
\quad \text { for Sri Lanka }\end{array}$ & $\begin{array}{l}\text { Examined in this } \\
\text { empirical analysis }\end{array}$ \\
\hline \multicolumn{4}{|l|}{ Maternal determinants } \\
\hline \multicolumn{4}{|l|}{ Historical factors } \\
\hline Short or long birth interval & $+1+$ & Yes [10] & Yes \\
\hline Previous history of preterm/LBW births & $H+$ & - & Yes \\
\hline Parity & + & Yes [10] & No \\
\hline Previous still births and abortions & + & - & Yes \\
\hline \multicolumn{4}{|l|}{ Demographic factors } \\
\hline Advanced maternal age & + & Yes [17] & Yes \\
\hline Adolescent mothers & + & Yes [10] & Yes \\
\hline Unmarried/cohabitation & + & - & No \\
\hline Mother's education & + & Yes $[10,13]$ & Yes \\
\hline Household wealth & + & Yes [13] & Yes \\
\hline Urban/rural residence & + & Yes [13] & Yes \\
\hline \multicolumn{4}{|l|}{ Nutritional factors } \\
\hline Iodized salt & + & Yes [18] & Yes \\
\hline \multicolumn{4}{|l|}{ Anatomical factors } \\
\hline Maternal BMI & + & Yes [17] & Yes \\
\hline Maternal height & H & Yes [10] & Yes \\
\hline Weight gain during pregnancy & + & Yes [19] & No \\
\hline Uterine factors & + & - & No \\
\hline Placental factors & + & - & No \\
\hline \multicolumn{4}{|l|}{ Maternal medical conditions } \\
\hline Anaemia & + & Yes $[10,20]$ & Yes \\
\hline \multicolumn{4}{|l|}{ Lifestyle-related factors } \\
\hline Smoking & $+1+$ & - & No \\
\hline Heavy alcohol use & $+1+$ & Yes [19] & No \\
\hline Sleep deprivation & + & Yes [19] & No \\
\hline Less walking hours & ++ & Yes [19] & No \\
\hline Standing for more than 2.5 hours a day & + & Yes [17] & No \\
\hline \multicolumn{4}{|l|}{ Environmental factors } \\
\hline Altitude & $+1+$ & - & Yes \\
\hline Environmental tobacco exposure & + & - & No \\
\hline Passive inhalation of cooking smoke & + & Yes [10] & Yes \\
\hline Exposure to physical and chemical hazards & + & Yes [19] & No \\
\hline Piped water inside dwelling & + & Yes [13] & Yes \\
\hline Poor neighbourhood & + & - & Yes \\
\hline \multicolumn{4}{|l|}{ Violence/maternal abuse } \\
\hline Violence or abuse & + & - & Yes \\
\hline \multicolumn{4}{|l|}{ Paternal determinants } \\
\hline Advanced paternal age & + & - & Yes \\
\hline Paternal history of being LBW & + & - & No \\
\hline Father's education & + & Yes $[10]$ & Yes \\
\hline \multicolumn{4}{|l|}{ Foetal determinants } \\
\hline Sex of child & ++ & Yes [10] & Yes \\
\hline Gestational duration & $+1+$ & Yes [10] & No \\
\hline Multiple birth & $+1+$ & Yes [13] & Yes \\
\hline
\end{tabular}

${ }^{1}$ Based on systematic review by Ohlsson and Shah (2008), supplemented by additional review by authors.

$2+++$ strong association, ++ modest association, + weak association. 
To allow analysis of living standards, household wealth indices were constructed based on household assets, using Principle Components Analysis (PCA), and households ranked into sample-weighted quintiles. Tabulation of LBW by household wealth quintiles was included for the first time in the DHS 2006/07 report, but we report this for the first time for prior DHS surveys. PCA was also applied to a number of variables concerning mother's participation in decision-making, and mothers divided into tertiles according to their level of autonomy.

Altitude is a determinant of LBW previously not examined in Sri Lanka [9]. The DHS 2006/07 survey recorded households' GPS coordinates. We derived the corresponding altitudes by referencing the NASA space shuttle generated global digital elevation database, SRTM1, via the GPS visualizer website (www. gpsvisualizer.com).

All statistical analyses were carried out using Stata, version 11.2 (Stata Corp, College Station, TX, USA), taking account of the multistage cluster sampling design of the surveys. During regression analyses, potential variable interactions were tested for, and multicollinearity of variables was assessed using variance inflation factors.

\section{Results}

Excluding EP and NP for valid comparison, the incidence of LBW declined substantially from $20.6 \%$ during $1987-1993$ to $17.2 \%$ during $1993-2000$, and then to $16.6 \%$ during 2000-2006/07 (Table 2). Including EP has negligible impact. These figures mask a large increase in LBW in the estate sector from $24 \%$ and $31 \%$ in the last two DHS surveys. The slow-down in LBW reduction since 2000 contrasts with rapid income growth nationally. Very low birth weight, defined as $\mathrm{BW}<1,500 \mathrm{~g}$, decreased from $0.9 \%$ to $0.8 \%$ and then to $0.6 \%$ during the three surveys.

Similar LBW disparities are observed in all surveys. LBW incidence is higher in first, female and multiple births, and when the pregnancy interval is short (proxied by birth interval $<1$ year) $[10,11]$. LBW is higher $(25-26 \%)$ in underweight mothers than those of normal weight (16$17 \%$ ), and least (11\%) in overweight mothers.

LBW incidence is higher in rural than urban areas, whilst in estate areas it is more than double (31\% versus $13 \%$ in DHS 2006/07). LBW increases with altitude in the DHS 2006/07, from $15 \%$ at the lowest elevations to $30 \%$ at the highest. LBW has concentrated in the plantation districts of Nuwara Eliya and Badulla, and in Trincomalee, with the lowest rates observed in the Western Province (Figure 1). LBW is twice as high in Indian Tamils and is lower in Moors, and decreases with maternal education.

The incidence of LBW is consistently higher the poorer the family, as proxied by wealth quintiles (Table 2). $\mathrm{LBW}$ rates in the poorest quintile are double those in the richest (DHS 2006/07: 22\% versus 12\%). This economic inequality is evident in each survey's concentration curve (Figure 2). The inequality represented in the concentration curve can be quantified using the concentration index (CI), whose value ranges from -1 to +1 , with a value of -1 indicating that the variable is concentrated in the poorest household, a value of zero when there is no inequality (represented by the line of equality), and +1 when it is concentrated in the richest household. The negative CI values for the surveys are highly significant $(p<0.001)$. Inequality increased from the DHS $1993(\mathrm{CI}=-0.14)$ to the DHS $2000(\mathrm{CI}=-0.20)$, before decreasing again in the DHS 2006/07 (CI=-0.13).

We then analysed determinants of LBW in the DHS 2006/07 using multivariate logistic regression. We selected variables based on a literature review of findings globally and in Sri Lanka (Table 1), and the UNICEF framework for determinants of childhood malnutrition [2, 3, 12]. Model building was done in a stepwise additive manner to estimate odds ratios (OR) for $\mathrm{LBW}$.

Several covariates with no significant impact were excluded during model building. These included iron supplements during pregnancy and use of iodised salt, which is consistent with weak evidence in the literature. Other dropped covariates include birth interval, previous stillbirths, abortions or miscarriages, taking medication for heart disease (proxy for heart disease), paternal age and education, use of firewood without a chimney for ventilation (linked to indoor air pollution), and neighbourhood living standards. Contrary to a previous World Bank study, access to piped water was not a determinant [13]. None of the variable interactions examined proved significant.

Some covariates that were significant at a $15 \%$ confidence level were retained, if the coefficients were logically causal. Final results are shown in Table 3, which presents the results for one intermediate model (Model A) and for the final model (Model B). Goodness-of-fit testing indicates that Model B is well calibrated (HosmerLemeshow statistic $1.025, p=0.42$ ).

The results confirm the strong influence of proximal determinants. The risk of LBW is significantly higher if the child is a first, female, multiple, or caesarean birth, and if the mother has a history of LBW. There is an increased $\mathrm{LBW}$ risk in the youngest mothers, although the coefficients are of borderline significance.

Maternal height and BMI are each large, highly significant determinants of LBW. The relative risk of LBW decreases by $5 \%$ for each $1 \mathrm{~cm}$ increase in height, and decreases by $8 \%$ for each unit increase in BMI, with detailed analysis revealing an approximately linear relationship in each case. Altitude is highly significant, with the relative risk increasing by $7 \%$ for every 100 meters increase in elevation above sea level. 
Table 2. Percentage of low birth weight by descriptive characteristics, DHS 1993, 2000 and 2006-07

\begin{tabular}{|c|c|c|c|c|}
\hline \multirow[t]{2}{*}{ Background characteristics ${ }^{1}$} & \multirow[t]{2}{*}{ DHS $1993^{1}$} & \multirow[t]{2}{*}{ DHS $2000^{1}$} & \multicolumn{2}{|c|}{ DHS 2006-07² } \\
\hline & & & Excluding EP & Including EP \\
\hline \multicolumn{5}{|l|}{ Child sex } \\
\hline Male & 18.7 & 15.8 & 15.4 & 15.2 \\
\hline Female & 22.7 & 18.7 & 17.8 & 17.8 \\
\hline \multicolumn{5}{|l|}{ Birth interval } \\
\hline 1st child & 21.8 & 21.6 & 20.7 & 20.9 \\
\hline $1-12$ months & 40.4 & 4.4 & 28.0 & 25.3 \\
\hline$>12$ months & 19.6 & 13.4 & 13.4 & 13.3 \\
\hline \multicolumn{5}{|l|}{ Low birth weight history } \\
\hline No & 19.7 & 16.7 & 16.3 & 16.2 \\
\hline Yes & 43.5 & 32.8 & 34.3 & 31.7 \\
\hline \multicolumn{5}{|l|}{ Birth type } \\
\hline Single & 18.7 & 16.9 & 15.3 & 15.3 \\
\hline Multiple & 79.3 & 41.3 & 73.5 & 73.9 \\
\hline \multicolumn{5}{|l|}{ Mother's age } \\
\hline $15-19$ & 22.7 & 15.7 & 30.2 & 28.4 \\
\hline $20-24$ & 24.3 & 22.3 & 21.2 & 21.5 \\
\hline $25-29$ & 20.1 & 19.4 & 15.7 & 15.4 \\
\hline $30-34$ & 17.0 & 14.8 & 15.0 & 14.8 \\
\hline $35-49$ & 21.9 & 12.5 & 15.5 & 15.6 \\
\hline \multicolumn{5}{|l|}{ Mother's BMI } \\
\hline Underweight $(\mathrm{BMI} \leq 18)$ & - & 25.1 & 26.4 & 26.3 \\
\hline Normal weight & - & 15.2 & 17.1 & 17.0 \\
\hline Overweight $(\mathrm{BMI} \geq 25)$ & - & 11.2 & 11.3 & 11.3 \\
\hline \multicolumn{5}{|l|}{ Mother's ethnicity } \\
\hline Sinhalese & 19.5 & 16.2 & 15.8 & 15.9 \\
\hline Sri Lanka Tamil & 19.8 & 17.9 & 19.8 & 19.4 \\
\hline Indian Tamil & 41.7 & 30.8 & 36.8 & 36.6 \\
\hline Moor & 17.0 & 14.1 & 14.9 & 13.9 \\
\hline \multicolumn{5}{|l|}{ Mother's education } \\
\hline No education & 32.9 & 36.4 & 34.0 & 30.5 \\
\hline Primary & 25.8 & 21.4 & 22.8 & 21.4 \\
\hline Secondary & 20.2 & 17.8 & 17.3 & 17.1 \\
\hline Higher & 15.2 & 12.6 & 13.5 & 13.6 \\
\hline \multicolumn{5}{|l|}{ Sector } \\
\hline Urban & 17.7 & 12.8 & 13.1 & 12.6 \\
\hline Rural & 19.9 & 17.0 & 16.3 & 16.3 \\
\hline Estate & 39.9 & 23.7 & 31.4 & 31.4 \\
\hline \multicolumn{5}{|l|}{ Altitude (meters) } \\
\hline $0-250$ & - & - & 15.2 & 15.3 \\
\hline $251-500$ & - & - & 17.4 & 17.4 \\
\hline $500-1,000$ & - & - & 22.4 & 22.4 \\
\hline$>1,000$ & - & - & 29.6 & 29.6 \\
\hline \multicolumn{5}{|l|}{ Wealth quintile } \\
\hline Poorest & 25.6 & 24.5 & 21.7 & 22.0 \\
\hline 2 & 24.7 & 19.8 & 22.2 & 21.0 \\
\hline 3 & 22.2 & 16.0 & 13.8 & 14.3 \\
\hline 4 & 16.1 & 14.1 & 15.3 & 15.5 \\
\hline Richest & 14.1 & 9.4 & 11.6 & 11.5 \\
\hline Total & 20.6 & 17.2 & 16.6 & 16.5 \\
\hline Concentration index (CI) & -0.14 & -0.20 & -0.13 & -0.13 \\
\hline Standard error in CI & 0.02 & 0.03 & 0.02 & 0.02 \\
\hline Number of observations (N) & 3,531 & 2,589 & 5,664 & 6,402 \\
\hline
\end{tabular}


Table 3. Adjusted odds ratios (95\% confidence intervals) of low birth weight by birth, parental, household and social characteristics, DHS 2006/07

\begin{tabular}{|c|c|c|c|c|c|}
\hline \multirow{3}{*}{ Category } & \multirow{3}{*}{ Characteristics } & \multicolumn{4}{|c|}{ Logistic regression: Low birth weight $(<2,500 \mathrm{~g})$} \\
\hline & & \multicolumn{2}{|c|}{ Model A } & \multicolumn{2}{|c|}{ Model B } \\
\hline & & $a O R^{1}$ & CI 95\% & $a O R^{1}$ & CI 95\% \\
\hline \multirow[t]{4}{*}{ Infant and birth factors } & First child & $1.77 * * *$ & $1.48-2.12$ & $1.81 * * *$ & $1.50-2.19$ \\
\hline & Female child & $1.25^{* *}$ & $1.07-1.45$ & $1.30 * * *$ & $1.11-1.52$ \\
\hline & Twin or multiple birth & $18.24 * * *$ & $11.20-29.71$ & $24.29 * * *$ & $14.69-40.17$ \\
\hline & Caesarean birth & $1.42 * * *$ & $1.18-1.69$ & $1.48^{* * *}$ & $1.23-1.79$ \\
\hline \multirow[t]{3}{*}{ Maternal birth factors ${ }^{2}$} & Age $<19$ years & $1.58 *$ & $1.09-2.28$ & 1.42 & $0.98-2.06$ \\
\hline & Age $19-23$ years & 1.19 & $0.97-1.45$ & 1.12 & $0.91-1.38$ \\
\hline & Prior LBW in past 5 years & & & $2.34 * * *$ & $1.52-3.59$ \\
\hline \multirow[t]{2}{*}{ Maternal size } & Maternal BMI & & & $0.92 * * *$ & $0.90-0.94$ \\
\hline & Mother's height $(\mathrm{cm})$ & & & $0.95 * * *$ & $0.93-0.96$ \\
\hline \multirow[t]{3}{*}{ Maternal education $^{2}$} & Primary & 0.70 & $0.45-1.09$ & 0.77 & $0.49-1.20$ \\
\hline & Secondary & $0.54 * *$ & $0.36-0.82$ & $0.59 *$ & $0.39-0.89$ \\
\hline & Higher & $0.43 * * *$ & $0.27-0.68$ & $0.47 * *$ & $0.29-0.75$ \\
\hline \multirow[t]{2}{*}{ Female autonomy (tertiles) ${ }^{2}$} & Middle & $0.71 * * *$ & $0.58-0.87$ & $0.69 * * *$ & $0.56-0.85$ \\
\hline & Highest & $0.74 * * *$ & $0.61-0.89$ & $0.77^{* *}$ & $0.64-0.93$ \\
\hline Post-tsunami birth ${ }^{3}$ & & 1.86 & $0.79-4.36$ & 1.73 & $0.81-3.67$ \\
\hline \multirow[t]{3}{*}{ Maternal medical care } & Treated for asthma & 1.46 & $0.93-2.28$ & 1.50 & $0.98-2.28$ \\
\hline & Treated for hypertension & 1.85 & $0.92-3.69$ & $2.31 *$ & $1.12-4.75$ \\
\hline & Family health worker visits & 0.97 & $0.95-1.00$ & $0.97 *$ & $0.94-1.00$ \\
\hline \multirow[t]{4}{*}{ Household wealth ${ }^{2}$} & Second quintile & 0.99 & $0.78-1.25$ & 1.11 & $0.88-1.41$ \\
\hline & Third quintile & $0.75^{*}$ & $0.57-0.97$ & 0.88 & $0.67-1.15$ \\
\hline & Fourth quintile & $0.75^{*}$ & $0.57-0.97$ & 1.02 & $0.78-1.34$ \\
\hline & Highest quintile & $0.62 * *$ & $0.45-0.84$ & 0.97 & $0.70-1.33$ \\
\hline Household size (persons) & & 1.00 & $0.96-1.04$ & 0.97 & $0.93-1.02$ \\
\hline \multirow[t]{4}{*}{ Maternal ethnicity ${ }^{2}$} & Sri Lankan Tamil & 1.23 & $0.92-1.64$ & 1.32 & $0.98-1.78$ \\
\hline & Indian Tamil & $2.24 * * *$ & $1.43-3.52$ & $1.84^{*}$ & $1.13-3.00$ \\
\hline & Sri Lanka Moor & 0.80 & $0.61-1.05$ & 0.90 & $0.69-1.17$ \\
\hline & Other & 1.07 & $0.34-3.30$ & 1.41 & $0.42-4.75$ \\
\hline \multirow[t]{2}{*}{ Sector ${ }^{2}$} & Rural & $1.33^{*}$ & $1.05-1.67$ & $1.28 *$ & $1.01-1.62$ \\
\hline & Estate & 1.32 & $0.85-2.04$ & 0.85 & $0.54-1.36$ \\
\hline Altitude (100m) & & & $1.07 * * *$ & $1.04-1.10$ & \\
\hline Number of observations (N) & & 6,374 & & 6,089 & \\
\hline
\end{tabular}

\footnotetext{
${ }^{1}$ Results of the multiple logistic regression analysis are given as adjusted odds ratios (aOR), with 95\% confidence intervals (CI). For noncategorical variables, the aOR represents the increase in relative risk of LBW per unit increase in the variable. Asterisks indicate significance of adjusted odds ratios: * $p<0.05, * * p<0.01, * * * p<0.001$.

${ }^{2}$ Reference categories are 24-49 years (for maternal age), no schooling (for maternal education), lowest tertile (for maternal autonomy), poorest quintile (for household wealth), Sinhalese (for maternal ethnicity), and urban (for sector).

${ }^{3}$ Births taking place in tsunami-affected households in the six months following 2004 Tsunami.
} 
Table 4. Adjusted odds ratios (95\% confidence intervals) of low birth weight by child and household characteristics including food security, NFSS 2009

\begin{tabular}{|c|c|c|c|c|c|}
\hline \multirow{3}{*}{ Category } & \multirow{3}{*}{ Characteristics } & \multicolumn{4}{|c|}{ Logistic regression: Low birth weight $(<2,500 \mathrm{~g})$} \\
\hline & & \multicolumn{2}{|c|}{ Model A } & \multicolumn{2}{|c|}{ Model B } \\
\hline & & $a O R^{1}$ & CI 95\% & $a O R^{1}$ & CI 95\% \\
\hline \multirow[t]{2}{*}{ Infant and birth factors } & Female child & $1.33 *$ & $1.06-1.66$ & $1.41 * *$ & $1.10-1.79$ \\
\hline & Twin or multiple birth & $12.05^{* * *}$ & $6.53-22.23$ & $13.07 * * *$ & $7.19-23.74$ \\
\hline \multirow[t]{3}{*}{ Maternal birth factors ${ }^{2}$} & $<19$ years & 1.28 & $0.76-2.13$ & 1.28 & $0.75-2.18$ \\
\hline & $19-23$ years & $1.36^{*}$ & $1.01-1.81$ & 1.28 & $0.94-1.73$ \\
\hline & Prior LBW in past 5 years & & & $2.79 * * *$ & $1.51-5.15$ \\
\hline \multirow[t]{2}{*}{ Maternal size } & Maternal BMI & & & $0.96 * *$ & $0.93-0.98$ \\
\hline & Mother's height $(\mathrm{cm})$ & & & $0.95 * * *$ & $0.92-0.96$ \\
\hline \multirow[t]{3}{*}{ Maternal education ${ }^{2}$} & Primary & 1.17 & $0.73-1.88$ & 1.09 & $0.63-1.86$ \\
\hline & Secondary & 0.96 & $0.64-1.43$ & 1.00 & $0.61-1.63$ \\
\hline & Higher & 0.86 & $0.52-1.41$ & 0.92 & $0.51-1.64$ \\
\hline Post-tsunami birth ${ }^{3}$ & & 1.18 & $0.67-2.05$ & 1.24 & $0.67-2.27$ \\
\hline Maternal anaemia $(<\mathbf{1 1} \mathbf{g} / \mathbf{d l})^{4}$ & & & & $1.70 * *$ & $1.20-2.41$ \\
\hline \multirow[t]{4}{*}{ Household wealth ${ }^{2}$} & Second quintile & 0.84 & $0.61-1.14$ & 0.88 & $0.63-1.21$ \\
\hline & Third quintile & $0.58 * *$ & $0.41-0.80$ & $0.62 * *$ & $0.43-0.87$ \\
\hline & Fourth quintile & $0.62 *$ & $0.41-0.92$ & 0.66 & $0.42-1.01$ \\
\hline & Highest quintile & $0.47 * * *$ & $0.31-0.70$ & $0.53 * *$ & $0.33-0.83$ \\
\hline Household size & & 0.99 & $0.91-1.06$ & 0.96 & $0.88-1.04$ \\
\hline \multirow[t]{4}{*}{ Religion (maternal) ${ }^{2}$} & Hindu & $0.75 *$ & $0.56-0.99$ & 0.75 & $0.54-1.01$ \\
\hline & Muslim & $0.58 * *$ & $0.41-0.82$ & $0.60^{*}$ & $0.39-0.89$ \\
\hline & Roman Catholic & 0.77 & $0.52-1.12$ & 0.88 & $0.58-1.32$ \\
\hline & Other & 0.86 & $0.31-2.36$ & 1.00 & $0.34-2.92$ \\
\hline \multirow[t]{2}{*}{ Sector $^{2}$} & Rural & 0.86 & $0.64-1.16$ & 0.83 & $0.60-1.14$ \\
\hline & Estate & $2.56 * * *$ & $1.65-3.95$ & $2.07 * *$ & $1.28-3.33$ \\
\hline \multirow[t]{4}{*}{ Food security indicators } & No. of food types consumed & & & 0.98 & $0.85-1.11$ \\
\hline & $\begin{array}{l}\text { No. of months food } \\
\text { insufficient in last year }\end{array}$ & & & 0.99 & $0.95-1.02$ \\
\hline & $\begin{array}{l}\text { Adult equivalent per capita } \\
\text { food expenditure }\end{array}$ & & & 1.00 & $0.99-1.00$ \\
\hline & $\begin{array}{l}\text { Received Thriposha in the } \\
\text { last } 6 \text { months }\end{array}$ & & & 1.27 & $0.88-1.81$ \\
\hline Number of observations (N) & & 3,885 & & 3,536 & \\
\hline
\end{tabular}

\footnotetext{
${ }^{1}$ Results of the multiple logistic regression analysis are given as adjusted odds ratios (aOR), with 95\% confidence intervals (CI). For noncategorical variables, the aOR represents the increase in relative risk of LBW per unit increase in the variable. Asterisks indicate significance of adjusted odds ratios: * $p<0.05, * * p<0.01, * * * p<0.001$.

${ }^{2}$ Reference categories are 24-49 years (for maternal age), no schooling (for maternal education), poorest quintile (for household wealth), Buddhist (for maternal religion), and urban (for sector).

${ }^{3}$ Births taking place in tsunami-affected households in the six months following 2004 Tsunami.

${ }^{4}$ Blood haemoglobin was measured at time of interview, which is after pregnancy.
} 

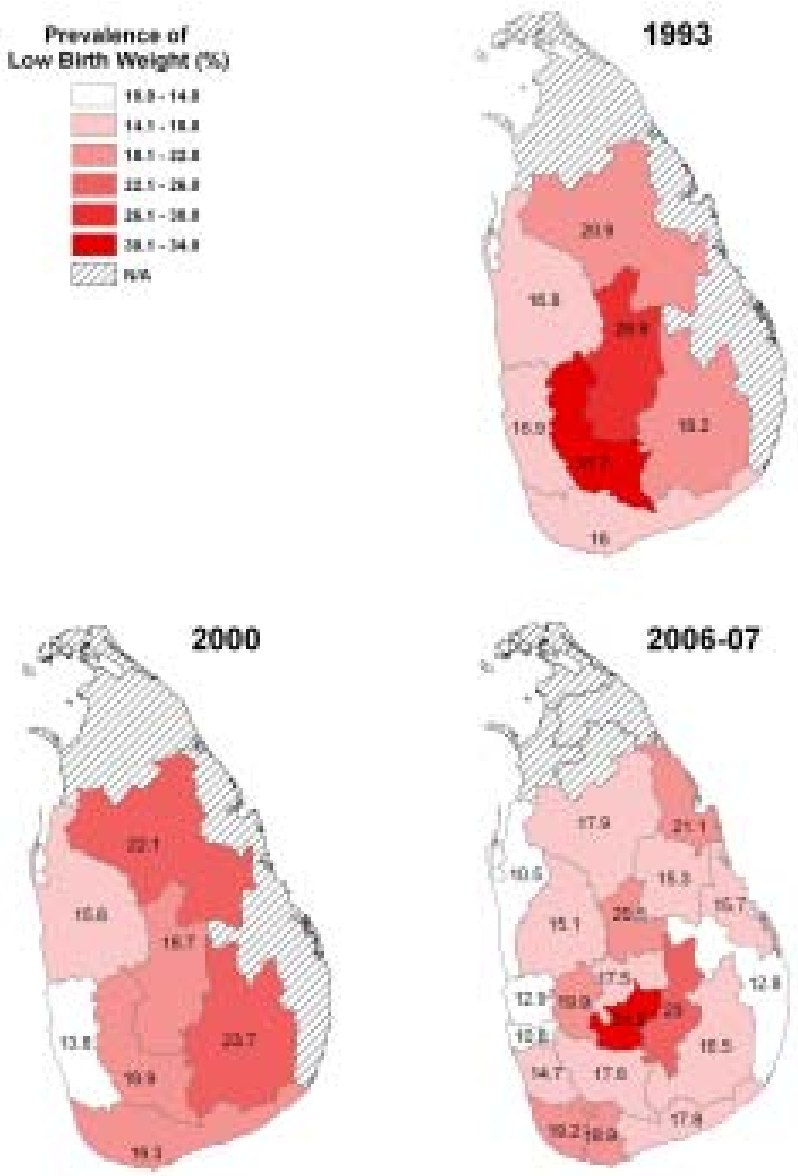

Figure 1. Geographical prevalence of low birth weight (\%), DHS 1993, 2000 and 2006-07

Source: Authors' estimates based on geographical areas represented in each survey's design.

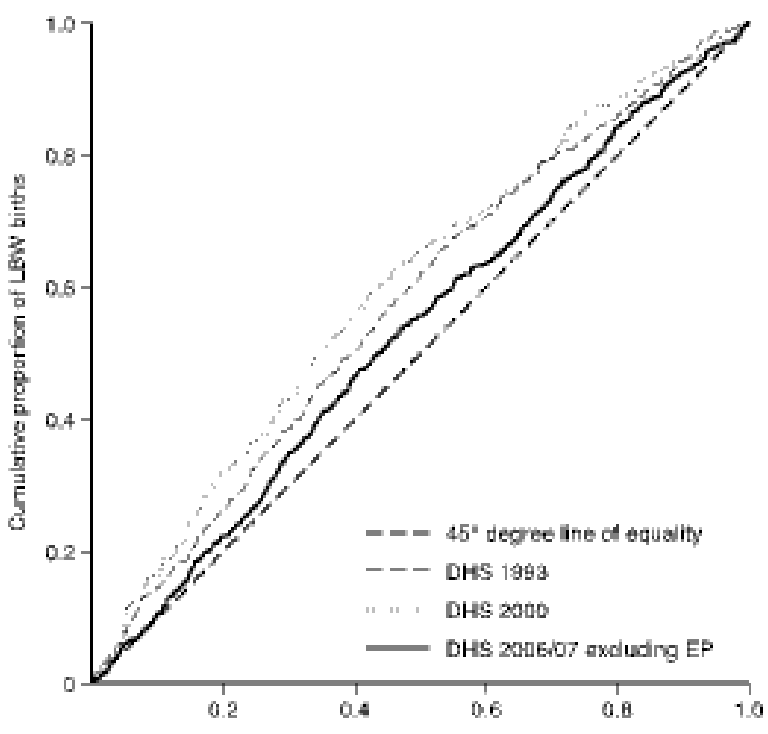

Curnulstive proportian of all bilths ranked from poorest to riches:

Figure 2. Concentration curves for low birth weight, DHS 1993, 2000 and 2006-07
LBW risk increases with maternal hypertension, reduced maternal education, and with reduced female autonomy, confirming other South Asian research [14]. There was an increased risk in tsunami-affected pregnancies (potential cause of maternal stress), and if the mother takes medications for asthma (proxy for asthma), although the coefficients were not significant at $5 \%$.

Once these determinants are controlled for, household wealth and sector have no independent influence on LBW risk. As illustrated by Models A and B, the impact of household wealth is eliminated when controlled for maternal height and BMI. This suggests that the largest part of the influence of economic status on LBW incidence is via access to food (mean BMI increases by 3.3 units from the poorest to richest quintiles), and via its correlation with maternal height, which increases by $3 \mathrm{~cm}$ between the poorest and richest quintiles. In addition, having controlled for altitude and other factors, estate sector residence is associated with a reduced LBW risk, but being Indian Tamil remains associated with an increased risk ( $\mathrm{OR}=1.84)$.

We similarly analysed the NFSS 2009 survey, which contains fewer variables, but has other variables related to household food security. The results of this are comparable (Table 4), and the final model is well calibrated (Hosmer-Lemeshow statistic 1.395, $p=0.188$ ). The highly significant odds ratio for estate residence is likely confounded by the omission of ethnicity, which is not available in the NFSS. However, none of the added food security variables are significant, including an increased risk of LBW associated with receiving 'Thriposha' in the past six months, which may reflect the targeting of 'Thriposha' to mothers at higher risk of LBW. The absence of the expected relationships may be because these indicators are not good measures of food security during the relevant pregnancy, since the impacts of maternal height and BMI are comparable to the DHS data.

To assess the relative contribution of the determinants to the economic inequalities, we analysed the CI in the DHS 2006/07, using the method of decomposition that exploits the mathematical property of the $\mathrm{CI}$ that it can be decomposed into a linear combination of concentration indices of its determinants [15]. This found that the largest single contribution $(21 \%)$ was made by maternal BMI, with other significant contributions being by infant and birth factors ( $15 \%)$, maternal education $(14 \%)$, wealth quintile (14\%), maternal height $(12 \%)$, ethnicity $(9 \%)$ and altitude (7\%).

\section{Discussion}

LBW incidence has declined in Sri Lanka to $17 \%$. In the richest households, rates are comparable to the 
$10-11 \%$ seen in UK-born South Asian mothers, suggesting that these households have closed the gap with their UK peers [16]. However, significant social inequalities in LBW exist, and some have worsened. Incidence is highest in the poor and Indian Tamils.

Our analysis identifies several factors that independently increase the risk of LBW. Some of these, such as multiple pregnancy or altitude, are not amenable to intervention. The critical determinants are maternal BMI, height and education. The impacts of maternal BMI and height are substantial, and controlling for them largely eliminates the association of LBW with poverty, and substantially reduces the risk associated with Indian Tamil ethnicity.

The BMI results imply that poverty leads to increased LBW through the mechanism of food insecurity, with poorer households having less adequate intake of food. Government food transfers, including 'Thriposha' for mothers, target poor families, but the results indicate these do not adequately mitigate food insecurity. This suggests the need for substantial changes in the effectiveness of these programmes, and for research into why recent economic growth has not translated into improved food security for the poorest.

Maternal height is a marker for the nutritional conditions that the mother was born in. Global evidence shows that inter-generational effects have large impacts on LBW, especially in poor settings, mediated by epigenetic mechanisms [3]. Although short stature, poverty and altitude explain a large part of the increased LBW incidence in Indian Tamils, a significant independent risk remains. This may be rooted in the colonial system of indentured labour that brought Indian Tamils to Sri Lanka in the 19th century, which targeted the poor and destitute. These effects and the persistence of a higher LBW incidence in South Asians in UK suggest that LBW incidence will change slowly, and that sustained, scaledup and targeted efforts are needed to reduce future LBW incidence in Sri Lanka [16].

Finally, the country needs to systematically track LBW incidence and determinants, including preterm birth, which we could not assess. Given Sri Lanka's circumstances, the country should emulate advanced nations by recording $\mathrm{BW}$ in the birth certificate, and making such data available for analysis.

\section{Acknowledgements}

The authors acknowledge financial support from UNICEF, Colombo (Agreement No. SSA/SRIA/2010/ 00003395-0) and the IHP Public Interest Research Fund (Grant No. PIRF-2011-03). We also thank the Department of Census and Statistics for making available the DHS data, and Dr. Renuka Jayatissa of the Medical Research
Institute for making available the NFSS data and for a suggestion regarding the potential role of altitude in undernutrition.

\section{References}

1. UNICEF. Reduction of Low Birth Weight: A South Asia Priority. Kathmandu, Nepal: UNICEF Regional Office for South Asia; 2002.

2. Ohlsson A, Shah P. Determinants and Prevention of Low Birth Weight: A Synopsis of the Evidence. Edmonton, Canada: Institute of Health Economics, 2008.

3. Ramakrishnan U. Nutrition and low birth weight: from research to practice. American Journal of Clinical Nutrition 2004; 79: 17-21.

4. Nube M. The Asian enigma: predisposition for low adult BMI among people of South Asian descent. Public Health Nutrition 2008; 12: 507-16.

5. Department of Census and Statistics Ministry of Finance, Planning, Ethnic Affairs and National Integration and Ministry of Health, Highways and Social Science. Demographic and Health Survey 1993. Colombo, Sri Lanka: Department of Census and Statistics, Ministry of Finance, Planning, Ethnic Affairs and National Integration in collaboration with Ministry of Health, Highways and Social Science, 1993.

6. Department of Census and Statistics (DCS), and Ministry of Health Nutrition and Welfare. Sri Lanka Demographic and Health Survey 2000. Colombo, Sri Lanka: Department of Census and Statistics in collaboration with Ministry of Health, Nutrition and Welfare, 2002.

7. Department of Census and Statistics (DCS), and Ministry of Healthcare and Nutrition (MOH). Sri Lanka Demographic and Health Survey 2006-07. Colombo, Sri Lanka: Department of Census and Statistics in collaboration with Ministry of Healthcare and Nutrition, 2009.

8. Jayatissa R, Hossaine SMM. Nutrition and Food Security Assessment in Sri Lanka 2009. Colombo, Sri Lanka: Medical Research Institute, UNICEF and World Food Programme, 2010.

9. Jensen GM, Moore LG. The Effect of High Altitude and Other Risk Factors on Birthweight: Independent or Interactive Effects? American Journal of Public Health 1997; 87: 1003-7.

10. Family Health Bureau Ministry of Health and Women's Affairs. Study on low birth weight and neonatal morbidity and mortality. Colombo, Sri Lanka: 1992.

11. Zhu B-P. Effect of interpregnancy interval on birth outcomes: findings from three recent US studies. International Journal of Gynecology and Obstetrics 2005; 89 (Supp 1): S25-S33.

12. UNICEF. Strategy for Improved Nutrition of Children and Women in Developing Countries. New York: UNICEF, 1990.

13. Shekar M, Somanathan A, Du L. Malnutrition in Sri Lanka: Scale Scope, Causes and Potential Response: World Bank 2007. 
14. Sethuraman K, Lansdown R, Sullivan K. Women's empowerment and domestic violence: The role of sociocultural determinants in maternal and child undernutrition in tribal and rural communities in South India Food and Nutrition Bulletin 2006; 27: 128-43.

15. Hosseinpoor AR, Van Doorslaer E, Speybroeck N, et al. Decomposing socioeconomic inequality in infant mortality in Iran. International Journal of Epidemiology 2006; 35: 1211-9.

16. Harding S, Rosato M, Cruickshank J. Lack of change in birthweights of infants by generational status among Indian, Pakistani, Bangladeshi, Black Caribbean, and Black African mothers in a British cohort study. International Journal of Epidemiology 2004; 33: 1279-85.

17. Abeysena C, Jayawardana P, De A Seneviratne R. Effect of psychosocial stress and physical activity on low birthweight: a cohort study. The Journal of Obstetrics and Gynaecology Research 2010; 36: 296-303.

18. Mason JB, Deitchler M, Gilman A, et al. Iodine fortification is related to increased weight-for-age and birthweight in children in Asia. Food and Nutrition Bulletin 2002; 23: 292-308.

19. Abeysena C, Jayawardana P, De A Seneviratne R. Maternal sleep deprivation is a risk factor for small for gestational age: a cohort study. The Australian and New Zealand Journal of Obstetrics and Gynaecology 2009; 49: 382-7.

20. Abeysena C, Jayawardana P, De A Seneviratne R. Maternal haemoglobin level at booking visit and its effect on adverse pregnancy outcome. The Australian and New Zealand Journal of Obstetrics and Gynaecology 2010; 50: 423-7. 